\title{
BMJ Open Hospitalisation for chronic obstructive pulmonary disease and risk of suicide: a population-based case-control study
}

\author{
Jennie Maria Christin Strid, ${ }^{1,2}$ Christian Fynbo Christiansen, ${ }^{1}$ Morten Olsen, ${ }^{1}$ \\ Ping Qin ${ }^{3,4}$
}

To cite: Strid JMC, Christiansen $\mathrm{CF}$, Olsen $\mathrm{M}$, et al. Hospitalisation for chronic obstructive pulmonary disease and risk of suicide: a populationbased case-control study. BMJ Open 2014;4:e006363. doi:10.1136/bmjopen-2014006363

- Prepublication history for this paper is available online. To view these files please visit the journal online (http://dx.doi.org/10.1136/ bmjopen-2014-006363).

Received 14 August 2014 Revised 25 September 2014 Accepted 29 September 2014

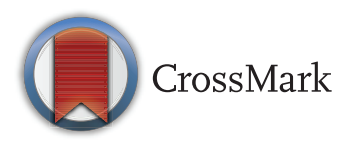

\footnotetext{
${ }^{1}$ Department of Clinical Epidemiology, Aarhus University Hospital, Aarhus $\mathrm{N}$, Denmark

2Department of

Anesthesiology and Intensive Care Medicine, Aarhus University Hospital, Aarhus C, Denmark

${ }^{3}$ National Centre for Registerbased Research, Aarhus University, Aarhus C, Denmark

${ }^{4}$ National Centre for Suicide Research and Prevention, Institute of Clinical Medicine, University of Oslo, Oslo, Norway
}

\section{Correspondence to} Dr Ping Qin; ping.qin@medisin.uio.no

\section{ABSTRACT}

Objectives: To examine risk of suicide among individuals with hospitalised chronic obstructive pulmonary disease (COPD) and to profile differences according to sex, age, psychiatric history, and recency and frequency of COPD hospitalisations.

Design: Nested case-control study.

Setting: Data were retrieved from Danish national registries.

Participants: All suicide cases aged 40-95 years deceased between 1981 and 2006 in Denmark ( $n=19869)$ and up to 20 live population controls per case matched on sex and date of birth $(n=321867$ controls).

Main outcome measures: The relative risk of suicide associated with COPD was computed using conditional logistic regression and adjusted for effects of psychiatric history and important sociodemographic factors.

Results: In our study population, $3 \%$ of suicide cases had been hospitalised for COPD compared with $1 \%$ of matched population controls. Thus, a hospitalised COPD was associated with a significantly increased risk for suicide (OR 2.6; 95\% $\mathrm{Cl} 2.3$ to 2.8). The increased risk remained significant after adjustment for psychiatric history and sociodemographic variables (OR 2.0; $95 \% \mathrm{Cl} 1.8$ to 2.2), and increased progressively with frequency and recency of COPD hospitalisation. At the same time, suicide risk associated with COPD differed significantly by sex, age and psychiatric status. The relative risk was more pronounced in women, in individuals older than 60 years and in persons with no history of psychiatric illness.

Conclusions: COPD confers an important risk factor for suicide completion. Risk assessment and prevention efforts should take patients' sex, age and psychiatric history into consideration.

\section{INTRODUCTION}

Chronic obstructive pulmonary disease (COPD) is characterised by progressive airflow limitation associated with abnormal pulmonary inflammation as a reaction to

\section{Strengths and limitations of this study}

- This study is based on data from five Danish national longitudinal registers, ensuring full representativeness, preciseness and minimum plausible recall bias of the data.

- Only hospitalised chronic obstructive pulmonary disease is considered in the analysis, and our finding relies on the quality of data in the source registers.

- The data cover a relatively long period, but we miss lifetime information for individuals included in the beginning of the study period and those at advanced ages.

irritating noxious particles and gases. ${ }^{12}$ The disease is common, especially among older people with previous tobacco smoking habits. ${ }^{3}$ The mortality rate of COPD has been rising since the 1990s and this disease is expected to be one of the leading causes of death worldwide in the next decades. ${ }^{4}$ COPD is associated with impaired quality of life, hypoxia, anxiety and depression-risk factors known for suicide. ${ }^{6-11}$ Although studies have reported an increased risk for suicide among patients with somatic illness, ${ }^{7}{ }^{12-14}$ to the best of our knowledge, few studies have examined the relationship between COPD and suicidal behaviour as the primary aim. A US study based on data from self-reported questionnaires showed an increased OR of lifetime suicidal ideation and suicide attempt in adults with COPD compared with those without COPD. ${ }^{15}$ Another cohort study on sociodemographic, psychiatric and somatic risk factors for suicide in Sweden reported an increased risk for suicide among women and men with COPD. ${ }^{7}$ Recently, two studies using data from the General Practice Research Database in the UK also demonstrated an increased risk of suicide and of self-harm that was associated with COPD among a number of 
physical diagnoses. ${ }^{16}{ }^{17}$ Similar findings were also reported in a study using regional population data from Canada. ${ }^{14}$ To extend our understanding on the relation of COPD with suicide risk, we conducted this large population study to document in detail the association between COPD and suicide risk according to factors around hospitalisation for COPD and by sex, age and psychiatric status of the patients.

\section{METHODS AND MATERIALS}

\section{Settings, study design and participants}

We conducted a nested case-control study based on all residents in Denmark (approximately 5.6 million). We retrieved data from five national longitudinal medical and administrative registries or databases, ${ }^{18-22}$ and linked the data at an individual-level using a unique personal identifier, assigned by the Danish Civil Registration System to all Danish citizens at birth and to new residents on immigration since April 1968. ${ }^{22}$

We identified all definite suicides ${ }^{23}{ }^{24}$ that occurred in 1981 through 2006 in Denmark by searching the Cause-of-Death Registry with the relevant diagnostic codes in the International Classification of Diseases, the 8th revision (ICD-8; E950-959) and the 10th revision (ICD-10; X60-84). The Cause-of- Death Registry has recorded the dates and causes of all deaths that have occurred in Denmark since the year $1969 .{ }^{19}$ Causes of death as well diagnoses of diseases are coded according to the Danish versions of the ICD-8 through 1993 and the ICD-10 since 1994. The 9th revision of ICD has never been introduced in Denmark. Sociodemographic status and labour market conditions (employment status, type of occupation, job function, employer) data for all Danish residents are collected in the Danish Integrated Database of Labor Market Research (IDA database). ${ }^{21}$ The individual sociodemographic data reported for a given calendar year are only complete for citizens living in Denmark on December 31 of the year in question. In order to have complete data on sociodemographic data from the IDA database, we restricted study cases to suicides residing in Denmark on 31 December of the preceding year. Moreover, we only included persons 4095 years old in the analyses, because COPD is rare in young people and it was difficult to find eligible controls for the very old.

Using incidence density sampling, ${ }^{25}$ we randomly drew up to 20 live population controls per suicide case, matched on sex and date of birth, from a $25 \%$ representative sample of the Danish population in the Civil Registration System. The rationale for using 20 controls per case, more than the recommended 3-5 controls per case, was because having extra controls did not require additional costs for data collection and could secure reasonable statistical power of analyses in the examination of uncommon exposures. The number of controls matched to each case in this study varied from 1 to 20 with an average of 16.2 controls per suicide case.

\section{Data on COPD and covariates}

To identify previous hospitalisations for COPD, we searched the Danish National Patient Registry (NPR) using the ICD-codes for COPD (ICD-8: 490-492 and ICD-10: J40-44). ${ }^{18}$ The Danish NPR contains data on all patient contacts with Danish somatic hospitals, including date of admission, up to 20 comorbid diagnoses and performed procedures, since the year 1977 for inpatients and 1995 for outpatients. ${ }^{18}$ All residents in Denmark have unrestricted free of charge access to outpatient and inpatient medical care through the tax-funded healthcare system. Private expenditure, if any, mainly goes in purchasing pharmaceuticals and dental care. We considered only severe COPD that led to hospitalisation for treatment in the analyses of the present study. We also recorded the total number and specific dates of all COPD hospitalisations in order to assess the influences of frequency of COPD hospitalisations (1-2, 3-5 and $>5$ hospitalisations) and of time elapsed since the last COPD hospitalisation (0-30 days, 1-6 months, 6-12 months, $1-3$ years, and $>3$ years between last hospitalisation for COPD and suicide).

To control for possible confounding effects of physical illness other than COPD, we retrieved data on previous hospitalisation for other physical illness from the NPR, excluding pregnancy and childbirth, mental and behavioural disorders and external causes (including accidental and intentional poisonings, and injuries), prior to the time of suicide or the matching date of control (index date). ${ }^{12}$

Personal data on contacts with psychiatric hospitals or wards, either as an inpatient or an outpatient, were retrieved from the Danish Psychiatric Central Registry. ${ }^{20}$ Data on inpatient admissions and discharges to psychiatric facilities in Denmark have been systematically collected in the Danish Psychiatric Central Registry since $1969 .^{20}$ Visits to hospital outpatient clinics and emergency departments have been recorded in the registry since 1995. We categorised the participants according to whether they had a contact with psychiatric hospitals or wards before the date of suicide or index date for controls.

Additionally, we retrieved personal sociodemographic data including annual gross income, place of residence and citizenship from the IDA database and marital status from the Civil Registration System, for the purpose of adjustment. ${ }^{23}$

\section{Statistical analysis}

We computed contingency tables for variables of interest as well as general characteristics of the study population. We used conditional logistic regression to estimate the association between hospitalisation for COPD and risk for subsequent suicide. Since we used incidence density sampling, the estimated ORs from the analyses were unbiased estimates of incidence rate ratios. ${ }^{25}$ To generate the associated ORs, we designed three different models: (I) crude, that is, only controlled for the effects 
of sex and birthdate through matching; (II) adjusted for personal history of psychiatric illness; and (III) further adjusted for gross income, place of residence, citizenship and marital status. The Wald test was used to test differences in OR estimates between groups and to examine interactions between COPD and sex, age and previous psychiatric illness. Stratified analyses by sex and age were performed to generate the effect of COPD on suicide in specific sexes and age groups. The interactive effect by psychiatric history was estimated by including the interaction of COPD and psychiatric history in the adjusted model for the total and for each specific sex and age group. Estimates of conditional logistic regression were generated using the PhReg procedure with each case forming a separate stratum. 95\% CI were computed and the level of statistical significance was set at $5 \%$. All statistical analyses were carried out in SAS V.9.2.

\section{RESULTS}

\section{General description}

We included 19869 cases who died from suicide between ages 40-95 years from the year 1981 through 2006 and 321867 matched controls randomly selected from a $25 \%$ representative sample of the national population. The majority of suicide cases were men $(\mathrm{n}=12548 ; 63.2 \%)$ and aged 40 to 60 years $(\mathrm{n}=10877$; $54.7 \%$; table 1$)$. In the study population, $3 \%(n=592)$ of suicide cases had a history of hospitalisation for COPD by the date of suicide compared with $1 \%(n=3087)$ of population controls. A larger proportion of suicide cases had a history of psychiatric illness $(n=8744 ; 44.0 \%)$ compared with the population controls $(n=19413 ; 6.0 \%)$. Suicide cases were also more frequent than the controls who had a physical illness other than COPD $(68.1 \%$ vs $48.8 \%$ ). At the same time, $36.5 \%$ of suicide cases had a yearly income at the lowest quartile level against $24.6 \%$ of the comparison controls. Moreover, suicide cases were mostly single $(52.2 \%)$, whereas the comparison controls were mostly married or cohabited with a partner (72.2\%; table 1$)$.

\section{Suicide risk associated with COPD}

We found that patients with a history of COPD hospitalisation were at a significantly increased risk of suicide compared with individuals without such a history (crude OR 2.6, $95 \%$ CI 2.3 to 2.8; table 2). The associated risk was attenuated slightly but remained highly significant after adjustment for psychiatric history, moreover adjusted for sociodemographic variables (adjusted OR $2.0,95 \%$ CI 1.8 to 2.2 ). The association was more pronounced in women than in men (adjusted OR: 2.3, 95\% CI 2.0 to 2.7 for women and $1.9,95 \%$ CI 1.6 to 2.1 for men; test of sex difference: $\left.\chi^{2}=4.17, \mathrm{p}=0.041\right)$ and in individuals aged 61-95 years than the younger group (adjusted OR: 2.2, 95\% CI 2.0 to 2.5 for 61-95 year olds and $1.5,95 \%$ CI 1.2 to 1.9 for $40-60$ year olds; test of age difference: $\chi^{2}=7.65, \mathrm{p}=0.005$; table 3 ).
Table 1 Characteristics of suicide cases and matched population controls

\begin{tabular}{|c|c|c|}
\hline \multirow[b]{2}{*}{ Variable } & \multicolumn{2}{|c|}{ Number distribution (in \%) } \\
\hline & $\begin{array}{l}\text { Suicide } \\
\text { cases }\end{array}$ & $\begin{array}{l}\text { Population } \\
\text { controls }\end{array}$ \\
\hline Total participants & $19869(100)$ & $321867(100)$ \\
\hline \multicolumn{3}{|c|}{ ( } \\
\hline Males & $12548(63.2)$ & $197997(61.5)$ \\
\hline Female & $7321(36.8)$ & $123870(38.5)$ \\
\hline \multicolumn{3}{|l|}{ Age group (years) } \\
\hline $40-60$ & $10877(54.7)$ & $207042(64.3)$ \\
\hline $61-95$ & 8992 (45.3) & $114825(35.7)$ \\
\hline \multicolumn{3}{|l|}{ History of COPD } \\
\hline Yes & $592(3.0)$ & $3087(1.0)$ \\
\hline No & $19277(97.0)$ & $318780(99.0)$ \\
\hline \multicolumn{3}{|l|}{ History of physical illness* } \\
\hline Yes & $13521(68.1)$ & $157193(48.8)$ \\
\hline No & 6348 (31.9) & $164674(51.2)$ \\
\hline \multicolumn{3}{|c|}{ History of psychiatric illness $†$} \\
\hline Yes & $8744(44.0)$ & $19413(6.0)$ \\
\hline No & $11125(56.0)$ & $302454(94.0)$ \\
\hline \multicolumn{3}{|l|}{ Gross income } \\
\hline $\begin{array}{l}\text { In the fourth/highest } \\
\text { quartile }\end{array}$ & $3906(19.7)$ & $80930(25.1)$ \\
\hline In the third quartile & $3991(20.1)$ & $80575(25.0)$ \\
\hline In the second quartile & $4730(23.8)$ & $81300(25.3)$ \\
\hline In the first quartile & $7242(36.4)$ & $79062(24.6)$ \\
\hline \multicolumn{3}{|l|}{ Place of residence } \\
\hline The capital area & $2953(14.9)$ & $33777(10.5)$ \\
\hline Provincial cities & $2065(10.4)$ & $34241(10.6)$ \\
\hline The remaining areas & $14851(74.7)$ & 253849 (78.9) \\
\hline \multicolumn{3}{|l|}{ Citizenship } \\
\hline Danish & $19612(98.7)$ & $316651(98.4)$ \\
\hline Other & $257(1.3)$ & $5216(1.6)$ \\
\hline \multicolumn{3}{|l|}{ Marital status } \\
\hline Married & $8426(42.4)$ & $214306(66.6)$ \\
\hline Cohabiting with a partner & $1074(5.4)$ & $17994(5.6)$ \\
\hline Single & $10369(52.2)$ & $89567(27.8)$ \\
\hline
\end{tabular}

*History of any somatic hospitalisation before date of suicide completion.

†History of specialist psychiatric care or hospitalisation before date of suicide completion.

COPD, chronic obstructive pulmonary disease.

We also noted that the relative risk of suicide progressively increased with an increasing frequency of COPD hospitalisations and with shorter time distance since last COPD hospitalisation (table 3). The adjusted OR for suicide increased from 1.8 (95\% CI 1.6 to 2.0) in patients with 1-2 previous COPD hospitalisations to 3.7 (95\% CI 2.5 to 5.4) in those with more than five COPD hospitalisations. At the same time, the adjusted OR for suicide declined from 8.3 (95\% CI 6.0 to 11.5 ) in patients hospitalised for COPD within the past 30 days to $1.2(95 \%$ CI 1.0 to 1.4$)$ in patients hospitalised for COPD more than 3 years ago. The observed pattern of ORs associated with the frequency and the recency of COPD hospitalisations remained similar in analyses stratified by sex and age group as well as by psychiatric history (data not shown). 
Table 2 Hospitalisation for COPD and associated OR for subsequent suicide

\begin{tabular}{|c|c|c|c|c|c|}
\hline \multirow[b]{2}{*}{ Variable } & \multicolumn{2}{|c|}{ Number distribution (in \%) } & \multicolumn{3}{|c|}{ OR $(95 \% \mathrm{CI})$ for suicide } \\
\hline & $\begin{array}{l}\text { Suicide cases } \\
n=19869(100)\end{array}$ & $\begin{array}{l}\text { Population controls } \\
\mathrm{n}=321867(100)\end{array}$ & Model I* & Model II† & Model III¥ \\
\hline \multicolumn{6}{|c|}{ History of hospitalised COPD } \\
\hline No & $19277(97.0)$ & $318780(99.0)$ & Reference & Reference & Reference \\
\hline Yes & $592(3.0)$ & $3087(1.0)$ & 2.6 (2.3 to 2.8$)$ & 2.1 (1.9 to 2.4$)$ & 2.0 (1.8 to 2.2$)$ \\
\hline \multicolumn{6}{|c|}{ Number of COPD hospitalisations } \\
\hline No COPD & $19277(97.0)$ & $318780(99.0)$ & Reference & Reference & Reference \\
\hline $1-2$ & $430(2.2)$ & $2598(0.8)$ & $2.2(2.0$ to 2.5$)$ & $1.9(1.7$ to 2.1$)$ & 1.8 (1.6 to 2.0$)$ \\
\hline $3-5$ & $116(0.6)$ & $344(0.1)$ & 4.3 (3.5 to 5.4$)$ & 3.4 (2.7 to 4.4$)$ & $3.2(2.5$ to 4.1$)$ \\
\hline$>5$ & $46(0.2)$ & $145(0.1)$ & 4.1 (2.9 to 5.8$)$ & 4.1 (2.8 to 6.0$)$ & 3.7 (2.5 to 5.4$)$ \\
\hline \multicolumn{6}{|c|}{ Time since last COPD hospitalisation } \\
\hline No COPD & $19277(97.0)$ & $318780(99.0)$ & Reference & Reference & Reference \\
\hline$<30$ days & $80(0.4)$ & $118(0.0)$ & 8.6 (6.4 to 11.6$)$ & 9.1 (6.59 to 12.55$)$ & $8.3(6.0$ to 11.5$)$ \\
\hline $1-6$ months & $131(0.7)$ & $377(0.1)$ & 4.6 (3.8 to 5.7$)$ & 4.1 (3.21 to 5.11$)$ & 3.8 (3.1 to 4.8$)$ \\
\hline 6-12 months & $63(0.3)$ & $305(0.1)$ & 2.8 (2.1 to 3.7$)$ & 2.4 (1.73 to 3.22$)$ & 2.2 (1.6 to 3.0$)$ \\
\hline $1-3$ years & $154(0.8)$ & $868(0.3)$ & 2.4 (2.0 to 2.9$)$ & 2.0 (1.62 to 2.38$)$ & 1.8 (1.5 to 2.2$)$ \\
\hline$>3$ years & $164(0.8)$ & $1419(0.4)$ & 1.5 (1.3 to 1.8$)$ & $1.2(1.01$ to 1.45$)$ & $1.2(1.0$ to 1.4$)$ \\
\hline
\end{tabular}

\section{Effect of COPD by psychiatric history}

Of individuals with a hospitalised COPD, a history of psychiatric disorder was more often seen in patients who died from suicide $(37.5 \%)$ than in counterpart live controls (11.8\%; table 4). Hence, the effect of COPD on suicide risk interacted significantly with psychiatric history (test of effect difference: $\chi^{2}=47.55, \mathrm{p}<0.001$ after adjustment for sociodemographic variables).

In general, a hospitalised COPD increased suicide risk significantly more in individuals with no recorded history of psychiatric illness (OR 2.6, 95\% CI 2.3 to 2.9 ) than it did for individuals with a psychiatric history (OR 1.2, 95\% CI 1.0 to 1.5) after having controlled for the main effect of psychiatric illness and the effects of socioeconomic factors. Regardless of sex and age, COPD denoted a significant risk factor for suicide in people without a psychiatric history. For individuals with a prior hospital contact because of psychiatric illness, the additional risk of suicide associated with COPD remained highly significant only in female participants and in patients above 60 years.

Table 3 Hospitalised COPD and associated OR for subsequent suicide, stratified by gender and age group

\begin{tabular}{|c|c|c|c|c|c|}
\hline \multirow[b]{2}{*}{ Exposure in study participants } & \multicolumn{2}{|c|}{ Number distribution (in \%) } & \multicolumn{3}{|c|}{ OR $(95 \% \mathrm{Cl})$ for suicide } \\
\hline & $\begin{array}{l}\text { Suicide cases } \\
n=19869\end{array}$ & $\begin{array}{l}\text { Population controls } \\
\mathrm{n}=321867\end{array}$ & Model I* & Model II† & Model III‡ \\
\hline \multicolumn{6}{|l|}{ Total participants } \\
\hline History of COPD: no & $19722(97.0)$ & 318780 (99.0) & Reference & Reference & Reference \\
\hline History of COPD: yes & $592(3.0)$ & $3087(1.0)$ & 2.6 (2.3 to 2.8$)$ & 2.1 (1.9 to 2.4$)$ & 2.0 (1.8 to 2.2$)$ \\
\hline \multicolumn{6}{|l|}{ Females } \\
\hline History of COPD: no & 7095 (96.9) & 122761 (99.1) & Reference & Reference & Reference \\
\hline History of COPD: yes & $226(3.1)$ & $1109(0.9)$ & 3.3 (2.8 to 3.8$)$ & 2.4 (2.0 to 2.9$)$ & 2.3 (2.0 to 2.8$)$ \\
\hline \multicolumn{6}{|l|}{ Males } \\
\hline History of COPD: no & $12182(97.1)$ & $196019(99.0)$ & Reference & Reference & Reference \\
\hline History of COPD: yes & $366(2.9)$ & $1978(1.0)$ & 2.2 (2.0 to 2.5$)$ & 2.0 (1.8 to 2.3$)$ & $1.9(1.6$ to 2.1$)$ \\
\hline \multicolumn{6}{|l|}{$40-60$ year olds } \\
\hline History of COPD: no & 10761 (98.9) & $206270(99.6)$ & Reference & Reference & Reference \\
\hline History of COPD: yes & $116(1.1)$ & $772(0.4)$ & 2.8 (2.3 to 3.5$)$ & 1.6 (1.3 to 2.1$)$ & 1.5 (1.2 to 1.9$)$ \\
\hline \multicolumn{6}{|l|}{$61-95$ year olds } \\
\hline History of COPD: no & $8516(94.7)$ & $112510(98.0)$ & Reference & Reference & Reference \\
\hline History of COPD: yes & $476(5.3)$ & $2315(2.0)$ & 2.4 (2.3 to 2.8$)$ & 2.3 (2.0 to 2.5$)$ & 2.2 (2.0 to 2.5$)$ \\
\hline
\end{tabular}


Table 4 Effect of hospitalised COPD on risk for subsequent suicide by psychiatric history

\begin{tabular}{|c|c|c|c|c|}
\hline \multirow[b]{2}{*}{ Participants by psychiatric history } & \multicolumn{2}{|c|}{ Number of participants with COPD } & \multicolumn{2}{|c|}{$\begin{array}{l}\text { OR }(95 \% \mathrm{Cl}) \text { for suicide } \\
\text { associated with COPD }\end{array}$} \\
\hline & Suicide cases & Population controls & Model I* & Model III† \\
\hline \multicolumn{5}{|l|}{ Total } \\
\hline Psychiatric history: no & 370 & 2722 & $2.8(2.5$ to 3.1$)$ & 2.6 (2.3 to 2.9$)$ \\
\hline $\begin{array}{l}\text { Psychiatric history: yes } \\
\text { Test of effect differences }\end{array}$ & 222 & 365 & $\begin{array}{l}1.3(1.1 \text { to } 1.5) \\
\chi^{2}=53.5 \\
p<0.001\end{array}$ & $\begin{array}{l}1.2(1.0 \text { to } 1.5) \\
\chi^{2}=47.6 \\
p<0.001\end{array}$ \\
\hline \multicolumn{5}{|l|}{ Males } \\
\hline Psychiatric history: no & 267 & 1781 & 2.5 (2.2 to 2.8$)$ & 2.3 (2.0 to 2.6$)$ \\
\hline $\begin{array}{l}\text { Psychiatric history: yes } \\
\text { Test of effect differences }\end{array}$ & 99 & 197 & $\begin{array}{l}1.1(0.8 \text { to } 1.4) \\
\chi^{2}=33.8 \\
p<0.001\end{array}$ & $\begin{array}{l}1.0(0.8 \text { to } 1.3) \\
\chi^{2}=30.0 \\
p<0.001\end{array}$ \\
\hline \multicolumn{5}{|l|}{ Females } \\
\hline Psychiatric history: no & 103 & 941 & 3.7 (3.0 to 4.6$)$ & 3.2 (2.8 to 4.4$)$ \\
\hline $\begin{array}{l}\text { Psychiatric history: yes } \\
\text { Test of effect differences }\end{array}$ & 123 & & $\begin{array}{l}1.5(1.2 \text { to } 1.9) \\
\chi^{2}=30.8 \\
p<0.001\end{array}$ & $\begin{array}{l}1.5(1.1 \text { to } 1.9) \\
\chi^{2}=28.5 \\
p<0.001\end{array}$ \\
\hline \multicolumn{5}{|l|}{$40-60$ year olds } \\
\hline Psychiatric history: no & 39 & 634 & $2.2(1.6$ to 3.1$)$ & $1.9(1.4$ to 2.7$)$ \\
\hline $\begin{array}{l}\text { Psychiatric history: yes } \\
\text { Test of effect differences }\end{array}$ & 77 & 138 & $\begin{array}{l}1.3(1.0 \text { to } 1.8) \\
\chi^{2}=5.3 \\
p=0.022\end{array}$ & $\begin{array}{l}1.2(0.9 \text { to } 1.7) \\
\chi^{2}=3.9 \\
p=0.048\end{array}$ \\
\hline \multicolumn{5}{|l|}{$61-95$ year olds } \\
\hline Psychiatric history: no & 331 & 2088 & 2.7 (2.4 to 3.1$)$ & 2.6 (2.3 to 3.0$)$ \\
\hline $\begin{array}{l}\text { Psychiatric history: yes } \\
\text { Test of effect differences }\end{array}$ & 145 & 227 & $\begin{array}{l}1.4(1.1 \text { to } 1.7) \\
\chi^{2}=27.9 \\
p<0.001\end{array}$ & $\begin{array}{l}1.3(1.1 \text { to } 1.7) \\
\chi^{2}=27.9 \\
p<0.001\end{array}$ \\
\hline
\end{tabular}

\section{DISCUSSION}

\section{Key findings and comparison with the literature}

In this large population study, we found a significantly increased risk of suicide among patients previously hospitalised for COPD compared with persons without a history of COPD hospitalisation. The relative risk remained highly significant after adjustment for psychiatric history and sociodemographic variables, and increased progressively with frequency and recency of COPD hospitalisation. In the meantime, suicide risk associated with COPD differed significantly by sex, age and psychiatric status; it was more pronounced in women, in individuals older than 60 years, and in persons with no history of psychiatric illness. These findings confirm previous reports on COPD being related to an elevated risk of suicidal ideation and suicide attempt or self-harm ${ }^{713-15} 17$ as well as suicide death. ${ }^{714} 16$ They extend the literature demonstrating that the effect of COPD on suicide risk differs significantly by sex, age and psychiatric status of the participants, and provide further insights into suicide risk in relation to recency and frequency of COPD hospitalisation for treatment.

In their studies, Goodwin et $a l^{13}$ found that physical illness including COPD and lung diseases are related to suicide attempts among adults in the USA. ${ }^{15}$ The authors also argued for a dose-response relationship between the number of diagnosed physical conditions and the risk of suicide attempt. This notion is supported by our findings of an elevated risk of suicide completion associated with multiple hospitalisations and recency of the last COPD hospitalisation. However, the studies of Goodwin et al were based on self-reported data on COPD, medical illness as well as suicidal behaviour from a cross-sectional questionnaire survey, while our study is based on routine data registered by clinicians and prospectively collected, without specific purposes, for research. Furthermore, the study of Goodwin et al included younger adults in whom COPD is less common, which complicates a direct comparison with the present study of participants 40-95 years of age. ${ }^{3}$

In a Swedish study on risk factors for suicide among adults during 2001-2008, Crump et $a l^{7}$ found that a previous diagnosis for COPD was a somatic risk factor for suicide in both women and men. Similarly, in two recent studies using data from the General Practice Research Database in the UK, Webb et $a l^{16}{ }^{17}$ found that COPD was among several somatic illnesses associated with a significantly increased risk of suicide and of self-harm; but the authors failed in detecting a highly significant sex difference in the effect of COPD on either suicide 
completion or self-harm, albeit the associated estimate of risk for suicide death was somewhat higher in women than in men. Furthermore, in a recent population-based study addressing suicide risk in relation to physical disorders, Bolton et $a l^{14}$ reported that women with COPD had almost five times the odds of suicide compared to women without COPD. Our findings are to a large extent in line with these studies but, compared to the studies of Crump et al and Webb et al, we further demonstrated a significantly stronger effect of COPD on risk for suicide in women than in men, although the observed OR for women in our study was not as large as in the study of Bolton et al. The observed sex difference in suicide risk associated with COPD echoes the earlier notion that women reacted more strongly towards physical functional problems than men did. ${ }^{23}$

The progressive increase of suicide risk with recency of being diagnosed or treated for physical illnesses has been reported in a number of studies on specific physical conditions such as cancer, ${ }^{14}{ }^{26}$ diabetes, ${ }^{27}$ multiple sclerosis, $^{28}$ allergy ${ }^{24}$ as well as other physical illnesses. ${ }^{12}$ A progressive increase of suicide risk associated with the severity of physical illness, measured by frequent hospitalisations, has also been noted in a few studies. ${ }^{12} 2628$ Our study extends the existing evidence that these observations are also applicable to the specific illness of COPD.

This study also adds to the literature by showing that the effect of COPD on suicide risk differs according to personal psychiatric status with a more prominent effect for persons without, rather than with, a psychiatric history, suggesting a possible mediating role of psychiatric illness on the link of COPD with the risk for suicide.

Clinically, COPD is often associated with physical impairment and decreased social and emotional quality of life. ${ }^{35629}$ Any worsening of the illness would have an effect on degrading the patient's physical function, quality of life as well as mental well-being, and thus accelerates the patient's wish to end her/his own life. This may well explain our observation of the progressively increased risk of suicide along with multiple hospitalisations and recency of hospitalisation, although we could not elucidate the possible influence of being hospitalised per se, because hospitalisation itself could also induce a certain level of stress on the patients.

Psychiatric illness is a well-known risk factor for suicide completion. ${ }^{30}$ Somatic patients having been treated for psychiatric problems may receive additional attention on possible suicidal behaviour than individuals who have never had any hospital contact because of psychiatric problems. ${ }^{7}$ Consequently, a diagnosis of COPD has a relatively smaller effect on risk of suicide for individuals with psychiatric comorbidity than for those without the comorbidity. Moreover, patients with psychiatric illness already have an increased suicide risk a priori, it is therefore understandable that the additional effect from COPD on suicide risk in these patients is not as strong as the effect of COPD in patients who have never received any specialist care or been hospitalised for psychiatric treatment. Also, the possible influence of psychiatric problems that are clinically undiagnosed or untreated may be contributable to the relatively strong effect of COPD in patients with no record of psychiatric history.

The strong association between COPD and suicide risk, as demonstrated in the present study and earlier studies, underlines the importance of mental healthcare for patients with COPD,${ }^{31}$ especially those recently discharged from hospital treatment or with multiple hospitalisations, female patients and patients of advanced ages. Assessment of suicide risk and prevention effort should take into account patients' sex, age and psychiatric history. Close collaboration of clinicians and clinical units with responsibility for COPD treatment with mental health professional and services would be of benefit to the patients, albeit precise recommendations should be supported by estimates of the absolute risk and number needed to treat. ${ }^{32}$

\section{Limitations and strengths}

The present study relies on the quality of COPD diagnosis in the Danish National Patient Register (NPR). Although $99.4 \%$ of hospitalisations are included in the $\mathrm{NPR}^{33}$ and the overall positive predictive value of acute COPD discharge diagnosis in the NPR is $92 \%$ (95\% CI 91 to $93 \%),{ }^{33} 34$ any incomplete diagnostic registrations, for example, substantial under recording of COPD during hospitalisations with other acute respiratory conditions, ${ }^{34}$ would have led to underestimation of the association.

Data on physical illness have been routinely and systematically recorded in the NPR since 1977, which means that we have many years of data on participants included in the end of the study period but might miss lifetime data on participants included in the beginning of the study period and also on individuals of high ages.

In the meantime, this study only considered patients with COPD previously hospitalised for treatment, leaving less severe or better-controlled COPD outpatients included in the reference group. This may result in an underestimation of the full extent of the association between COPD and subsequent suicide risk. Similarly, a contact with psychiatric hospitals and specialist clinics was used as a proxy for psychiatric illness, which represents more severe psychiatric conditions, possibly leading to an underestimation of psychiatric problems.

On the other hand, the data used for the study have been collected systematically and routinely without any purpose of fulfilling a particular interest of research, which reduces plausible bias due to recall of information and ensures the precision of the data. At the same time, the study is based on the entire national population of a country where hospital treatments for physical and psychiatric illness are free of charge, which eliminates possible bias induced by a selection of access to healthcare by personal socioeconomic status. The large size of included participants also provides us opportunities to search insights on effect differences by, for example, sex 
and age as well as psychiatric history with reasonable statistical power.

\section{CONCLUSIONS}

The present study demonstrates a substantially increased risk of suicide among patients previously hospitalised for COPD compared with individuals without such a history. The relative risk increases with frequency of hospitalisations and recency of the most recent hospitalisation for COPD treatment. The observed effect was more prominent in women, in patients above 60 years old and in individuals without a psychiatric history. The findings underline the importance of assessment of suicide risk in patients with COPD and the need of close collaboration between clinicians and clinic units with responsibilities of somatic and psychiatric treatment.

Contributors $P Q$ conceptualised and designed the study and analysed the data. JMCS reviewed the literature, organised the writing and wrote the initial drafts. $P Q$ and JMCS finalised the manuscript. JMCS, CFC, MO and PQ contributed the analysis and interpretation of the data, revised critically for important intellectual content and approved the final version to be published.

Funding This project was partly supported by the Danish Sygekassernes Helsefonden (Danish Health Insurance Research foundation; 2009B063).

\section{Competing interests None.}

Ethics approval The study has been approved by the Data Protection Agency in Denmark.

Provenance and peer review Not commissioned; externally peer reviewed.

Data sharing statement No additional data are available. Statistical code and further explanation about the data set can be provided from the corresponding author on request.

Open Access This is an Open Access article distributed in accordance with the Creative Commons Attribution Non Commercial (CC BY-NC 4.0) license, which permits others to distribute, remix, adapt, build upon this work noncommercially, and license their derivative works on different terms, provided the original work is properly cited and the use is non-commercial. See: http:// creativecommons.org/licenses/by-nc/4.0/

\section{REFERENCES}

1. Lash $T L$, Johansen MB, Christensen S, et al. Hospitalization rates and survival associated with COPD: a nationwide Danish cohort study. Lung 2011;189:27-35.

2. Littner MR. In the clinic. Chronic obstructive pulmonary disease. Ann Intern Med 2011;154:ITC4-1-15; quiz ITC4-16.

3. Rennard SI. COPD: overview of definitions, epidemiology, and factors influencing its development. Chest 1998;113(4 Suppl):235s-41s.

4. Atsou K, Chouaid C, Hejblum G. Variability of the chronic obstructive pulmonary disease key epidemiological data in Europe: systematic review. BMC Med 2011;9:7.

5. Donaldson GC, Wedzicha JA. COPD exacerbations.1: Epidemiology. Thorax 2006;61:164-8.

6. Anzueto A. Impact of exacerbations on COPD. Eur Respir Rev 2010;19:113-18.

7. Crump C, Sundquist K, Sundquist J, et al. Sociodemographic, psychiatric and somatic risk factors for suicide: a Swedish national cohort study. Psychol Med 2014;44:279-89.
8. Mikkelsen RL, Middelboe T, Pisinger C, et al. Anxiety and depression in patients with chronic obstructive pulmonary disease (COPD). A review. Nord J Psychiatry 2004;58:65-70.

9. Ninot G. [Anxiety and depression in COPD: a review]. Rev Mal Respir 2011;28:739-48.

10. Tan WC. Factors associated with outcomes of acute exacerbations of chronic obstructive pulmonary disease. COPD 2004;1:225-47.

11. Willgoss $\mathrm{T}$, Yohannes $\mathrm{A}$, Goldbart $\mathrm{J}$, et al. COPD and anxiety: its impact on patients' lives. Nurs Times 2011;107:16-19.

12. Qin P, Webb R, Kapur N, et al. Hospitalization for physical illness and risk of subsequent suicide: a population study. $J$ Intern Med 2013;273:48-58.

13. Goodwin RD, Marusic A, Hoven CW. Suicide attempts in the United States: the role of physical illness. Soc Sci Med 2003;56:1783-8.

14. Bolton JM, Walld R, Chateau D, et al. Risk of suicide and suicide attempts associated with physical disorders: a population-based, balancing score-matched analysis. Psychol Med 2014. [Epub ahead of print 17 Jul 2014].

15. Goodwin RD. Is COPD associated with suicide behavior? $J$ Psychiatr Res 2011;45:1269-71.

16. Webb RT, Kontopantelis E, Doran T, et al. Suicide risk in primary care patients with major physical diseases: a case-control study. Arch Gen Psychiatry 2012;69:256-4.

17. Webb RT, Kontopantelis E, Doran T, et al. Risk of self-harm in physically ill patients in UK primary care. J Psychosom Res 2012;73:92-7.

18. Andersen TF, Madsen M, Jorgensen J, et al. The Danish National Hospital Register. A valuable source of data for modern health sciences. Dan Med Bull 1999;46:263-8.

19. Juel K, Helweg-Larsen K. The Danish registers of causes of death. Dan Med Bull 1999;46:354-7.

20. Munk-Jorgensen P, Mortensen PB. The Danish Psychiatric Central Register. Dan Med Bull 1997;44:82-4.

21. Denmark S. Integrated Database for Labour Market Research (IDA). Secondary Integrated Database for Labour Market Research (IDA). http://www.dst.dk/en/Statistik/dokumentation/Declarations/ integrated-database-for-labour-market-research--ida-.aspx

22. Pedersen CB, Gotzsche H, Moller JO, et al. The Danish Civil Registration System. A cohort of eight million persons. Dan Med Bull 2006;53:441-9.

23. Qin P, Agerbo E, Mortensen PB. Suicide risk in relation to socioeconomic, demographic, psychiatric, and familial factors: a national register-based study of all suicides in Denmark, 1981-1997. Am J Psychiatry 2003;160:765-72.

24. Qin P, Mortensen PB, Waltoft BL, et al. Allergy is associated with suicide completion with a possible mediating role of mood disorder -a population-based study. Allergy 2011;66:658-64.

25. King G, Zeng L. Estimating risk and rate levels, ratios and differences in case-control studies. Stat Med 2002;21:1409-27.

26. Allebeck $P$, Bolund $C$, Ringback $G$. Increased suicide rate in cancer patients. A cohort study based on the Swedish Cancer-Environment Register. J Clin Epidemiol 1989;42:611-16.

27. Goodwin RD, Marusic A, Hoven CW. Diabetes and suicidal ideation among youth in the community. Arch Pediatr Adolesc Med 2002;156:841.

28. Fredrikson $\mathrm{S}$, Cheng $\mathrm{Q}$, Jiang $\mathrm{GX}$, et al. Elevated suicide risk among patients with multiple sclerosis in Sweden. Neuroepidemiology 2003;22:146-52.

29. Tottenborg SS, Thomsen RW, Nielsen $\mathrm{H}$, et al. Improving quality of care among COPD outpatients in Denmark 2008-2011. Clin Respir J 2013;7:319-27.

30. Hawton K, van Heeringen K. Suicide. Lancet 2009;373:1372-81.

31. Hegerl U, Mergl R. Depression and suicidality in COPD: understandable reaction or independent disorders? Eur Respir $J$ 2014;44:734-3.

32. Taur FM, Chai S, Chen MB, et al. Evaluating the suicide risk-screening scale used by general nurses on patients with chronic obstructive pulmonary disease and lung cancer: a questionnaire survey. J Clin Nurs 2012;21:398-407.

33. Nickelsen TN. [Data validity and coverage in the Danish National Health Registry. A literature review]. Ugeskr Laeger 2001;164:33-7.

34. Thomsen RW, Lange $\mathrm{P}$, Hellquist $\mathrm{B}$, et al. Validity and underrecording of diagnosis of COPD in the Danish National Patient Registry. Respir Med 2011;105:1063-8. 